Discussion Paper No. 1039

\title{
TECHNOLOGY SPILLOVERS AND OUTSIDE OPTIONS IN A BILATERAL DUOPOLY
}

\author{
Noriaki Matsushima \\ Laixun Zhao
}

August 2018

The Institute of Social and Economic Research

Osaka University

6-1 Mihogaoka, Ibaraki, Osaka 567-0047, Japan 


\title{
Technology spillovers and outside options in a bilateral duopoly ${ }^{*}$
}

\author{
Noriaki Matsushima ${ }^{\dagger}$ Laixun Zhao ${ }^{\ddagger}$
}

August 6, 2018

\begin{abstract}
This paper examines the role of outside options in a downstream duopoly with exclusive vertical relations as in the Japanese automobile industry. In our setup, the downstream firms have outside options, and two upstream firms with exclusive relations can engage in cost reducing investments. More interestingly, each upstream firm can choose whether to voluntarily generate technology spillovers to its rival. We show that better outside options of the downstream firms can induce voluntary technology spillovers in the upstream level, increasing the profits of all firms on the vertical chain.
\end{abstract}

Keywords: Strategic sourcing, Outside option, Spillovers, Vertical relations

JEL Codes: L13, O32, M11, C72

*This paper is a part of the paper circulated under the title "Strategic dual sourcing as a driver for free revealing of innovation" (2015, ISER Discussion Paper No. 936). We divide the discussion paper into the two papers. This paper consists of Sections 1, 3, 4, and 5 in the discussion paper and a new explanation for the related real-world case. Another one, Matsushima and Zhao (2018), consists of Section 2 in the discussion paper and a new introduction. We are grateful to Eric Avenel, Carmen Beviá-Baeza, Yongmin Chen, Jay Pil Choi, Stefano Colombo, Wolfgang Gick, Junichiro Ishida, Atsushi Kajii, Inés Macho-Stadler, Masaki Nakabayashi, Ryoji Ohdoi, David Pérez-Castrillo, Joel Sandonís-Díez, Tadashi Sekiguchi, Tetsuya Shimane, Takashi Shimizu, Ken-Ichi Shimomura, Zhaohui Wu and seminar participants in APIOC2016 (Melbourne), Kobe University, MaCCI2015 (Mannheim), Osaka University, Tokyo Institute of Technology, and Universitat d'Alacant for their helpful comments. We would also like to thank Cong Pan and Shohei Yoshida for research assistance. The first author thanks the warm hospitality at MOVE, Universitat Autònoma de Barcelona where part of this paper was written and a financial support from the "Strategic Young Researcher Overseas Visits Program for Accelerating Brain Circulation" by JSPS. We gratefully acknowledge financial support from JSPS Grant-in-Aid for Scientific Research (S) Nos. JP26220503, JP15H05728, (A) No. JP17H00984, (B) Nos. JP24330079, JP15H03349, JP18H00847 and (C) No. JP24530248 and JP18K01593, and the program of the Joint Usage/Research Center for 'Behavioral Economics' at ISER, Osaka University. The usual disclaimer applies.

${ }^{\dagger}$ Corresponding author: Noriaki Matsushima, Institute of Social and Economic Research, Osaka University, Mihogaoka 6-1, Ibaraki, Osaka 567-0047, Japan. Phone: +81-6-6879-8571. E-mail: nmatsush@iser.osaka-u.ac.jp.

$\ddagger$ Laixun Zhao, Research Institute of Economics and Business, Kobe University, Rokkodai 2-1, Kobe, Hyogo 657-8501, Japan. Phone: +81-78-803-7006. E-mail: zhao@rieb.kobe-u.ac.jp. 


\section{Introduction}

While downstream manufactures depend on the cooperation of upstream intermediate suppliers (sometimes even with exclusive bilateral contracts), often the manufacturers would try to induce some kind of competition among suppliers, such as encouraging independent investments. For instance, Japanese firms bring rival parts suppliers to work together in some situations, while in other situations they keep the suppliers away from each other (Asanuma, 1985). ${ }^{1}$ Such practices still exist even today, and they create not only cooperation but also competition between suppliers within the network (Wilhelm, 2012).

Under such coexistence of cooperation and competition in the upstream level, downstream manufacturers tend to have long-term relations with suppliers (see examples of Toyota and Honda in Aoki and Lennerfors (2013)). In addition, they encourage the suppliers to engage in cost/quality improvements by using threats of their outside options/suppliers (e.g., Wu and Choi, 2005; Wilhelm, 2012). Kamath and Liker (1994) report that Japanese automakers would invite guest engineers from rival suppliers to compete side-by-side, to see who could come up with a better design. ${ }^{2}$ Moreover, even a long-term buyer-supplier relationship does not prevent the buyer from finding alternative suppliers to create competition (Wu and Choi, 2005). ${ }^{3}$

Given these stylized facts, in this paper, we examine how the threats of outside options can be used strategically to influence the incentives of suppliers to engage in cost-reducing or quality-upgrading investment, in a framework of downstream compe-

\footnotetext{
${ }^{1}$ Sourcing strategies have been discussed by management researchers since Porter (1980), who view multiple sourcing as a mechanism for a firm to affect its bargaining power relative to both inside and outside suppliers, which is what we rigorously model here.

${ }^{2}$ For instance, Dyer and Nobeoka (2000) that document the actual practices in Toyota.

${ }^{3}$ In another study, Wu et al. (2010) simulate such "co-opetition," where competing suppliers work together to meet the needs of the buyer.
} 
tition with vertical relations and endogenous outside options. We consider a bilateral duopoly in which two downstream buyers can make efforts to enrich their own outside options (e.g., searching for other suppliers and/or keeping in-house substitutable input production) and two upstream suppliers can engage in cost-reducing investments (e.g., R\&D). Moreover, before they engage in their efforts, each upstream firm is able to determine if it wants to generate technological spillovers to its rival upstream firm. This market structure follows the practices in the Japanese automobile industry, and we wish to investigate the incentives behind them, instead of considering other schemes such as technology licensing.

We find surprisingly that each supplier has an incentive to unilaterally generate a technology spillover to its rival for free, if its own downstream buyer can find cheap alternative sourcing. Such a strategy causes a market-size shrink within the vertical chain, which can hurt the downstream buyer but benefit the supplier, via dampening the buyer's effort to enrich its outside option. We show that the unilateral spillovers are strategic complements in the sense that it can induce the rival to also generate a technology spillover; and the resulted cross spillovers can benefit both the buyers and the suppliers.

Our results provide rationale for why the Japanese "suppliers' associations" still have strong support from both suppliers and auto makers (see Sako, 1996), even though these associations may at times generate outward spillovers to rivals. ${ }^{4}$ In Figure 1, we illustrate the structure in the Japanese automobile industry. Both exclusiveness within vertical chains and multiple memberships by very large auto-parts suppliers coexist. One might think that the parties on an exclusive vertical chain would worry about technological spillovers by the very large suppliers in an association, because such spillovers may help

\footnotetext{
${ }^{4}$ See also Aoki and Lennerfors (2013), for an analysis of the recent transformation of vertical keiretsu in the Japanese automotive industry.
} 
the rival vertical chains. However, as Sako (1996) and Aoki and Lennerfors (2013) show, the suppliers' associations remain stable, as the logic behind our result would indicate. ${ }^{5}$ Large suppliers would typically join in several suppliers' associations and hold multiple memberships, aiming at obtaining information on production plans and soliciting suggestion for common problems such as standardization and pollution control, etc., examples include Akebono Brake, Bridgestone, Denso, etc. ${ }^{6}$ Simultaneously, longterm relationships and even exclusive dealings within vertical chains are observed in Toyota and Honda (Aoki and Lennerfors, 2013). ${ }^{7}$ In addition, as mentioned earlier, a long-term buyer-supplier relationship does not prevent the buyer from finding alternative suppliers to create competition (Wu and Choi, 2005).

[Figure 1 about here]

Our bilateral duopoly model contributes to the literature of vertical relationships. Many researchers in the literature investigate the effects of disagreement payoffs on realized outcomes in buyer-supplier relations (e.g., Davidson, 1988; Horn and Wolinsky, 1988; Inderst, 2007; Milliou and Petrakis, 2007; Iozzi and Valletti, 2014, Inderst and

\footnotetext{
${ }^{5}$ Sako (1996) finds that the suppliers' associations are effective in diffusing innovative practices and sharing information in the automobile industry. In the 1990s, almost all major Japanese auto manufacturers (except Honda) have suppliers' associations, and many suppliers join multiple associations (Sako, 1996, p.651). Note that Aoki and Lennerfors (2013, p.79) point out that Honda also established suppliers' associations similar to other automakers, although the word 'keiretsu' is not used.

${ }^{6}$ Sako (1996. p.656) points out that main suppliers "employ around 3500 workers on average, and produce brake systems, bearings, springs, spark plugs, tyres, belting and batteries. They tend to play a leading role in association activities, by taking on chairmanship and executive positions in association committees and meetings." In the main model of the present paper, for analytical simplicity, we do not explicitly incorporate common suppliers. We expect that such an extension would not qualitatively affect our main results due to the symmetric impact of common suppliers on each vertical chain (except the case of one-sided spillover).

${ }^{7}$ Aoki and Lennerfors (2013) also find that the number of Toyota keiretsu members who also participate in the Nissan keiretsu is stable but that of Nissan keiretsu members who also participate in the Toyota keiretsu increased since 2003 (see their Table 2), confirming that the findings in Sako (1996) are still true in the current Japanese automobile industry.
} 
Shaffer, 2018). Our model further extends the literature by incorporating upstream firms' cost-reducing efforts with endogenous technology spillovers, and shows the abovementioned interesting results.

Note that Feng and Lu (2012) also use a similar market structure as ours to examine bilateral duopoly, and show that a simultaneous efficiency improvement of both suppliers can harm the downstream firm although the total industry profits rise. However, their results are obtained based on asymmetric bargaining powers for the upstream and downstream firms, which are not required in our model.

Several other papers investigate cases in which downstream firms engage in R\&D and endogenously determine the degree of R\&D spillovers. ${ }^{8}$ Kultti and Takalo (1998) and Poyago-Theotoky (1999) discuss whether downstream duopolists generate R\&D spillover after determining their investment levels, while in Kamien and Zang (2000), Gil-Moltó et al. (2005), and Milliou (2009), downstream firms noncooperatively set the degree of R\&D spillover before setting investment levels. ${ }^{9}$ Milliou (2009) shows that oligopolists prefer generating outward R\&D spillover if the degree of product differentiation is high enough, a result that does not hold if the products are homogenous as in our paper.

Elsewhere, the literature has investigated knowledge disclosure among competing firms. ${ }^{10}$ Pérez-Castrillo and Sandonís (1997) discuss know-how disclosure in a research joint venture although the main concern is free-riding problems. ${ }^{11}$ De Fraja (1993), Katsoulacos and Ulph (1998), and Pacheco-de-Almeida and Zemsky (2012) study environments where free revealing of knowledge can appear, in the context of continuous-time

\footnotetext{
${ }^{8}$ De Bondt (1997) and Rockett (2012) nicely survey the literature of R\&D competition.

${ }^{9}$ In Kamien and Zang (2000), no firm has an incentive to generate spillover. In Gil-Moltó et al. (2005), given that spillover is reciprocal, firms have incentives to generate a positive degree of spillovers.

${ }^{10}$ In the management literature, see Harhoff et al. (2003) for voluntary information spillovers and Pénin (2007) for open knowledge transfer.

${ }^{11}$ Subsequent researches further investigate the effectiveness of research joint ventures and cooperative R\&D (e.g., Pastor and Sandonís, 2002; Gil-Moltó et al., 2005).
} 
R\&D competition without vertical relation. And finally, Milliou and Petrakis (2012) show that a vertically integrated firm chooses to fully disclose its production knowledge to the downstream rival to expand downstream production, which eventually benefits the integrated upstream sector. Their result is less likely to hold if the degree of product differentiation is low. ${ }^{12}$ In contrast to the above, our paper provides another rationale behind such behavior, based on bargaining and outside options.

The present paper while simple, generates novel results that match the real practices of many firms on vertically related production networks, such as the automobile makers and parts suppliers documented in the literature. We explicitly demonstrate conventionally counterintuitive situations when the supplier may lose from a market expansion and when it may choose to give out its own technology to rivals. Our mechanism has wide applications under different circumstances, for instance, suppliers' incentives in cost reduction, quality improvement, upstream collaboration and technology spillovers, and even worker training in the labor market.

The rest of the paper proceeds as follows. Section 2 provides a model of bilateral duopoly with the downstream firms' outside options and cost-reducing activities by the upstream suppliers. Section 3 shows the main results. Section 4 concludes the paper. In the Appendix, we show several outcomes in Section 3.

\section{The model}

We examine a bilateral duopoly with two pairs of downstream and upstream firms, denoted by $D_{i}$ and $U_{i}$ respectively $(i=1,2)$. To produce a unit of the final product, firm $D_{i}$ needs one unit of the input produced by firm $U_{i}$ but not $U_{j}$. However, $D_{i}$ has outside options: it can procure the input from a different source at the price $\tilde{w}_{i}\left(e_{i}\right)=w-e_{i}$

\footnotetext{
${ }^{12}$ Yoshida (2015) shows that a downstream firm may have incentives to give superior technology to its rival in a downstream multi-product duopoly, where product multiplicity and the existence of strong upstream bargaining power are the key factors. The logic is quite different from ours.
} 
if the negotiation with $U_{i}$ breaks down, where $e_{i}$ is the search effort of $D_{i}$, with a cost of $S\left(e_{i}\right)$. Simultaneously, $U_{i}$ engages in cost-reducing activities such as process R\&D, through which it can reduce its marginal cost to $c-I_{i}$, where $I_{i}$ is the investment of $U_{i}$ at a cost of $f\left(I_{i}\right)$. We assume $c(<w)$ to be constant to ensure an interior solution.

Aoki and Lennerfors (2013) point out that long-term relationships and exclusiveness within vertical chains are observed in Toyota and Honda. In the present model, we can justify this relationship as follows: if $U_{i}$ has a long-term trading relationship with $D_{i}$, it obtains a cost-advantage relative to $U_{j}$, because $U_{i}$ and $D_{i}$ can often communicate faceto-face to improve on cost and quality. Such communication intensifies and becomes especially important, as the product characteristic complicates. But maintaining a longterm relationship is very costly so each branch has just one such relationship.

We then take into account technological spillovers between upstream firms, i.e., the cost-reducing effort by $U_{j}$ spills over to $U_{i}$. To obtain clear-cut results, following Milliou (2009), here we explicitly solve the game with linear demand and specific investment functions; $p=a-q_{1}-q_{2}, S\left(e_{i}\right)=\gamma e_{i}^{2}$, and $f\left(I_{i}\right)=\gamma I_{i}^{2}$, where $q_{i}$ is the quantity supplied by $D_{i}$, and $a(>c)$ and $\gamma$ are positive constants. We assume that the marginal cost of $U_{i}$ is $c-I_{i}-r I_{j}$ if $U_{j}$ chooses to give its reduced cost to $U_{i}$, where $r \in[0,1]$ is the exogenous degree of knowledge spillover. ${ }^{13}$ For notational simplicity, we define the marginal cost of $U_{i}$ as follows:

$$
c_{i}\left(I_{i} ; s_{j}\right)=\left\{\begin{array}{lll}
c-I_{i} & \equiv c_{i}\left(I_{i}\right) & \text { if } U_{j} \text { does not spill over }\left(s_{j}=0\right) \\
c-I_{i}-r I_{j} & \equiv c_{i}\left(I_{i}, I_{j}\right) & \text { if } U_{j} \text { spills over }\left(s_{j}=1\right)
\end{array}\right.
$$

Consider the following game structure. In the first stage, each upstream firm simultaneously determines whether to unilaterally generate spillover to its upstream rival. In the second stage, each of the four firms simultaneously sinks an investment cost that

\footnotetext{
13 The formulation of spillovers follows those in the related literature on research joint ventures (see for instance, Amir et al., 2003; Choi, 1993, d'Aspremont and Jacquemin, 1988; and Suzumura, 1992), although those papers consider scenarios in which firms conduct joint R\&D in the first stage and then compete in the product market in the second stage.
} 
determines the effort level to improve its outside option (downstream firms) or to reduce its marginal cost (upstream firms). In the third stage, observing the effort levels in the second stage, the upstream and the downstream firms on the same vertical chain negotiate over a transfer payment (a two-part tariff). The determined transfer payment is privately known in the vertical chain, but unknown to outsiders. This assumption simplifies the analysis because the Nash equilibrium wholesale price is set at the marginal cost of the upstream firm on each vertical chain. ${ }^{14}$ If an agreement is reached, the downstream firm procures its input from the upstream firm; otherwise, the downstream firm exercises its outside option. For expositional simplicity, we omit the fixed cost. Finally, in the fourth stage, all downstream firms simultaneously set quantities to maximize their own profits. The game is solved by backward induction.

\section{Results}

Before we proceed the analysis, we denote the gross final stage profit (excluding investments costs sunk in the second stage) on the vertical chain $i$ as $\pi_{i}\left(c_{i}, c_{j}\right)$, where $c_{i}$ and $c_{j}$ are respectively the marginal costs on the vertical chains $i$ and $j$, and $T_{i}$ as the payment from the downstream to the upstream firm when bargaining reaches an agreement. Then $\pi_{i}\left(c_{i}, c_{j}\right)-T_{i}$ is the gross profit of $D_{i}$, excluding investment costs already sunk in the second stage, and $T_{i}$ becomes the gross profit of $U_{i}$. Note that to obtain the net profit of each firm, the sunk cost of investment in the second stage must be subtracted from the above.

\subsection{The third and the forth stages}

From the forth-stage game, given that the marginal cost of $D_{i}$ is $d_{i}$, as in the standard Cournot duopoly outcome, the quantity supplied by $D_{i}$ and the final-stage gross profit

\footnotetext{
${ }^{14}$ Notice the difference from a case where contract terms are used as a commitment device to foster aggressive behavior at the downstream level (e.g., Fershtman and Judd, 1987).
} 
on the vertical chain $i$ are given as respectively

$$
q_{i}\left(d_{i}, d_{j}\right)=\frac{a+d_{j}-2 d_{i}}{3}, \text { and } \pi_{i}\left(d_{i}, d_{j}\right)=\left(q_{i}\left(d_{i}, d_{j}\right)\right)^{2}, \quad i, j=1,2, j \neq i .
$$

If $D_{i}$ and $U_{i}$ reach an agreement, $d_{i}$ is $c_{i}\left(I_{i} ; s_{j}\right)$ in $(1)$; otherwise, it is $\tilde{w}_{i}\left(e_{i}\right)$.

In the third stage, the pair $D_{i}$ and $U_{i}$ on the same vertical chain $i$ maximize the following Nash product with respect to $T$ :

$$
G_{i}=\left[\pi_{i}\left(c_{i}, c_{j}\right)-T_{i}-\pi_{i}\left(\tilde{w}_{i}, c_{j}\right)\right] T_{i}
$$

where $\pi_{i}\left(\tilde{w}_{i}, c_{j}\right)$ and 0 are respectively their gross profits if bargaining breaks down. Optimization gives

$$
T_{i}^{*}=\frac{\pi_{i}\left(c_{i}, c_{j}\right)-\pi_{i}\left(\tilde{w}_{i}, c_{j}\right)}{2}
$$

Then substitution yields the net profits as respectively

$$
\begin{aligned}
& \Pi_{i}^{U}=T_{i}^{*}-f\left(I_{i}\right)=\frac{\pi_{i}\left(c_{i}, c_{j}\right)-\pi_{i}\left(\tilde{w}_{i}, c_{j}\right)}{2}-f\left(I_{i}\right), \\
& \Pi_{i}^{D}=\pi_{i}\left(c_{i}, c_{j}\right)-T_{i}^{*}-S(e)=\frac{\pi_{i}\left(c_{i}, c_{j}\right)+\pi_{i}\left(\tilde{w}_{i}, c_{j}\right)}{2}-S(e) .
\end{aligned}
$$

Remark on equations (3) and (4) A decrease in $c_{j}$ reduces $q_{i}$, inducing $D_{i}$ to lower $e_{i}$, which decreases $\pi_{i}\left(\tilde{w}_{i}, c_{j}\right)$ through an increase in $\tilde{w}_{i}$ indirectly. Simultaneously, the decrease in $c_{j}$ also directly lowers both $\pi_{i}\left(c_{i}, c_{j}\right)$ and $\pi_{i}\left(\tilde{w}_{i}, c_{j}\right)$.

\subsection{The second stage: Spillover effects}

In the second stage, we consider three scenarios: (i) no upstream firm generates spillover;

(ii) only one upstream firm generates spillover; (iii) both upstream firms generate spillovers.

We then compare them and see which one comes on top. 


\subsubsection{No spillovers}

First, we look into the case when no upstream firm generates spillover to its rival. In the investment stage, from (3) and (4), the objective functions are given as

$$
\begin{aligned}
\Pi_{i}^{U} & =\frac{\pi_{i}\left(c_{i}\left(I_{i}\right), c_{j}\left(I_{j}\right)\right)-\pi_{i}\left(\tilde{w}_{i}\left(e_{i}\right), c_{j}\left(I_{j}\right)\right)}{2}-f\left(I_{i}\right), \\
\Pi_{i}^{D} & =\frac{\pi_{i}\left(c_{i}\left(I_{i}\right), c_{j}\left(I_{j}\right)\right)+\pi_{i}\left(\tilde{w}_{i}\left(e_{i}\right), c_{j}\left(I_{j}\right)\right)}{2}-S\left(e_{i}\right) .
\end{aligned}
$$

The first-order conditions lead to the reaction functions:

$$
I_{i}\left(I_{j}\right)=\frac{\alpha-I_{j}}{9 \gamma-2}, \quad e_{i}\left(I_{j}\right)=\frac{\alpha-2 \beta-I_{j}}{9 \gamma-2}
$$

where

$$
\alpha \equiv a-c \text { and } \beta \equiv w-c
$$

Note that $e_{i}\left(I_{j}\right)$ in $(7)$ includes only the investment level of the rival's upstream firm $U_{j}$ because $D_{i}$ 's effort is related to its outside option, $\pi_{i}\left(\tilde{w}_{i}\left(e_{i}\right), c_{j}\left(I_{j}\right)\right)$. Solving the simultaneous equations, we have the investment levels:

$$
I_{i}^{*}=\frac{\alpha}{9 \gamma-1}, \quad e_{i}^{*}=\frac{(9 \gamma-2) \alpha-2(9 \gamma-1) \beta}{(9 \gamma-2)(9 \gamma-1)} .
$$

The net profit of each firm then becomes

$$
\begin{aligned}
& \Pi_{i}^{U *}(N, N)=\frac{(9 \gamma-2) \gamma \alpha^{2}}{2(9 \gamma-1)^{2}}-\frac{9 \gamma^{2}((9 \gamma-2) \alpha-2(9 \gamma-1) \beta)^{2}}{2(9 \gamma-1)^{2}(9 \gamma-2)^{2}} \\
& \Pi_{i}^{D *}(N, N)=\frac{9 \gamma^{2} \alpha^{2}}{2(9 \gamma-1)^{2}}+\frac{\gamma((9 \gamma-2) \alpha-2(9 \gamma-1) \beta)^{2}}{2(9 \gamma-1)^{2}(9 \gamma-2)}
\end{aligned}
$$

where $k$ and $l$ in $\Pi_{i}^{U *}(k, l)$ and $\Pi_{i}^{D *}(k, l)$ respectively represent the decisions of upstream firms 1 and 2 for generating spillover $(k, l=Y, N)$, with $Y$ and $N$ indicating yes and no.

\subsubsection{One-sided spillover}

Next, consider the case in which only the reduced cost of $U_{1}$ is spilled over to $U_{2}$ but not the other way around. The cost function of $U_{2}$ can be rewritten as $c_{2}\left(I_{2}, I_{1}\right)=c-I_{2}-r I_{1}$ 
(see (1)). From (3) and (4), the objective functions of the firms are respectively

$$
\begin{aligned}
\Pi_{1}^{U} & =\frac{\pi_{1}\left(c_{1}\left(I_{1}\right), c_{2}\left(I_{2}, I_{1}\right)\right)-\pi_{1}\left(\tilde{w}_{1}\left(e_{1}\right), c_{2}\left(I_{2}, I_{1}\right)\right)}{2}-f\left(I_{1}\right), \\
\Pi_{1}^{D} & =\frac{\pi_{1}\left(c_{1}\left(I_{1}\right), c_{2}\left(I_{2}, I_{1}\right)\right)+\pi_{1}\left(\tilde{w}_{1}\left(e_{1}\right), c_{2}\left(I_{2}, I_{1}\right)\right)}{2}-S\left(e_{1}\right), \\
\Pi_{2}^{U} & =\frac{\pi_{2}\left(c_{2}\left(I_{2}, I_{1}\right), c_{1}\left(I_{1}\right)\right)-\pi_{2}\left(\tilde{w}_{2}\left(e_{2}\right), c_{1}\left(I_{1}\right)\right)}{2}-f\left(I_{2}\right), \\
\Pi_{2}^{D} & =\frac{\pi_{2}\left(c_{2}\left(I_{2}, I_{1}\right), c_{1}\left(I_{1}\right)\right)+\pi_{2}\left(\tilde{w}_{2}\left(e_{2}\right), c_{1}\left(I_{1}\right)\right)}{2}-S\left(e_{2}\right) .
\end{aligned}
$$

Then, the effort level of $U_{1}, I_{1}$, influences the outside value of $D_{1}, \pi_{1}\left(\tilde{w}_{1}\left(e_{1}\right), c_{2}\left(I_{2}, I_{1}\right)\right)$, as well as the downstream profit, $\pi_{1}\left(c_{1}\left(I_{1}\right), c_{2}\left(I_{2}, I_{1}\right)\right)$. The voluntary spillover generates a strategic interaction between the endogenous effort levels of $U_{1}$ and $D_{1}$, through $\pi_{1}\left(\tilde{w}_{1}\left(e_{1}\right), c_{2}\left(I_{2}, I_{1}\right)\right)$. An increase in $I_{1}$ decreases $c_{2}$, inducing $D_{1}$ to lower $e_{1}$. This effect can benefit $U_{1}$ especially when $\tilde{w}_{1}\left(e_{1}\right)$ is small because the marginal effect of lowering $e_{1}$ on the outside profit of $D_{1}$ increases as its "efficiency," $\tilde{w}_{1}\left(e_{1}\right)$, improves.

In the investment stage, each firm's reaction function is obtained as respectively

$$
\begin{aligned}
I_{1}\left(I_{2}, e_{1}\right) & =\frac{\alpha-r \beta-I_{2}+r e_{1}}{9 \gamma-2(1-r)}, \\
I_{2}\left(I_{1}\right) & =\frac{\alpha-(1-2 r) I_{1}}{9 \gamma-2}, \\
e_{1}\left(I_{2}, I_{1}\right) & =\frac{\alpha-2 \beta-I_{2}-r I_{1}}{9 \gamma-2}, \\
e_{2}\left(I_{1}\right) & =\frac{\alpha-2 \beta-I_{1}}{9 \gamma-2} .
\end{aligned}
$$

$e_{2}\left(I_{1}\right)$ is the same in both (7) and (15). Note that the technology spillover generates three additional effects on these reaction functions. First, the effort by $D_{1}$ enhances the incentive of $U_{1}$ to engage in cost reduction (see (12)), because the spillover allows $U_{1}$ to directly decrease the outside profit of $D_{1}$ through its own investment. Second, the effort by $U_{1}$ can increase the incentive of $U_{2}$ if the degree of spillover is large (see (13)), which is similar to that in the context of research joint ventures (e.g., d'Aspremont and Jacquemin, 1988). Finally, the effort by $U_{1}$ lowers the incentive of $D_{1}$ to increase 
its outside value (see (14)), similar to the reason in the first effect. Putting these all together, the spillover generates a positive impact on the efficiency of the rival upstream firm but a negative one on the downstream partner's effort to improve its outside option. The former impact hurts the technology giver while the latter one benefits it, and which effect is bigger can be explained as follows.

Solving the simultaneous equations gives:

$$
\begin{aligned}
I_{1}^{*}= & \frac{(3 \gamma-1)(9 \gamma-2+r) \alpha-3 \gamma(9 \gamma-2) r \beta}{(9 \gamma-2+r)((9 \gamma-1)(3 \gamma-1)+3 \gamma r)}, \\
I_{2}^{*}= & \frac{(3 \gamma-1+r)(9 \gamma-2+r) \alpha+3 \gamma(1-2 r) r \beta}{(9 \gamma-2+r)((9 \gamma-1)(3 \gamma-1)+3 \gamma r)}, \\
e_{1}^{*}= & \frac{(3 \gamma-1)(9 \gamma-2+r) \alpha-\left(2(3 \gamma-1)(9 \gamma-1)+(12 \gamma-1) r-3 \gamma r^{2}\right) \beta}{(9 \gamma-2+r)((9 \gamma-1)(3 \gamma-1)+3 \gamma r)}, \\
e_{2}^{*}= & \frac{((3 \gamma-1)(9 \gamma-2)+3 \gamma r)(9 \gamma-2+r) \alpha}{(9 \gamma-2)(9 \gamma-2+r)((9 \gamma-1)(3 \gamma-1)+3 \gamma r)} \\
& \quad-\frac{\left(2(3 \gamma-1)(9 \gamma-2)(9 \gamma-1)+\left(2-30 \gamma+81 \gamma^{2}\right) r+6 \gamma r^{2}\right) \beta}{(9 \gamma-2)(9 \gamma-2+r)((9 \gamma-1)(3 \gamma-1)+3 \gamma r)} .
\end{aligned}
$$

Further substitution yields the firms' equilibrium profits, which are messy algebraically (see Appendix): $\Pi_{1}^{U *}(Y, N), \Pi_{1}^{D *}(Y, N), \Pi_{2}^{U *}(Y, N)$, and $\Pi_{2}^{D *}(Y, N)$, given that the cost reduction of $U_{1}$ is spilled over to $U_{2}$.

Using the above, we can explicitly derive the threshold value of $\beta$, denoted as $\beta(Y N)$, at which $U_{1}$ 's profit when it voluntarily generates spillover equals that when it does not. A simple comparison leads to:

Proposition $1 \Pi_{1}^{U^{*}}(Y, N)>\Pi_{1}^{U^{*}}(N, N)$ if and only if $\beta<\beta(Y N)$, where $\beta(Y N)$ is the threshold $\beta$ satisfying $\Pi_{1}^{U^{*}}(Y, N)=\Pi_{1}^{U^{*}}(N, N)$. Similarly, $\Pi_{2}^{U^{*}}(N, Y)>\Pi_{2}^{U^{*}}(N, N)$ if and only if $\beta<\beta(Y N)$.

The threshold value $\beta(Y N)$ is depicted in Figure 2. $U_{1}$ benefits by giving its technology to the rival for free, if the above condition is satisfied. Similarly, we can numerically 
show that giving $U_{1}$ 's technology to $U_{2}$ harms $D_{1} \cdot{ }^{15}$

[Figure 2 about here]

\subsubsection{Two-sided spillovers}

Finally, we examine the case when both $U_{1}$ and $U_{2}$ cross spillover, specifically, the cost function of $U_{i}$ is given by $c_{i}\left(I_{i}, I_{j}\right)=c-I_{i}-r I_{j}(i, j=1,2, j \neq i$, see (1)). Except this ex-post cost of the upstream firms, the timing structure of the game is similar to the case under one-sided spillover just examined. From (3) and (4), the objective functions of $U_{i}$ and $D_{i}$ are given as respectively $(i, j=1,2$ and $j \neq i)$

$$
\begin{aligned}
\Pi_{i}^{U} & =\frac{\left(\pi_{i}\left(c_{i}\left(I_{i}, I_{j}\right), c_{j}\left(I_{j}, I_{i}\right)\right)-\pi_{i}\left(\tilde{w}_{i}\left(e_{i}\right), c_{j}\left(I_{j}, I_{i}\right)\right)\right)}{2}-f\left(I_{i}\right), \\
\Pi_{i}^{D} & =\frac{\left(\pi_{i}\left(c_{i}\left(I_{i}, I_{j}\right), c_{j}\left(I_{j}, I_{i}\right)\right)+\pi_{i}\left(\tilde{w}_{i}\left(e_{i}\right), c_{j}\left(I_{j}, I_{i}\right)\right)\right)}{2}-S\left(e_{i}\right) .
\end{aligned}
$$

Rearranging the first-order conditions, $\partial \Pi_{i}^{U} / \partial I_{i}=0$ and $\partial \Pi_{i}^{D} / \partial e_{i}=0$, gives the following reaction functions

$$
\begin{aligned}
I_{i}\left(I_{j}, e_{i}\right) & =\frac{\alpha-r \beta-(1-r)^{2} I_{j}+r e_{i}}{9 \gamma-2(1-r)}, \\
e_{i}\left(I_{i}, I_{j}\right) & =\frac{\alpha-2 \beta-r I_{i}-I_{j}}{9 \gamma-2} .
\end{aligned}
$$

Under reciprocal spillovers, the reaction function of $U_{i}$ in (18) differs from that in (12). However, the reaction function of $D_{i}$ in (19) is the same with that in (14), because the outside profit does not depend on the inside transfer price, $c_{i}\left(I_{i}, I_{j}\right)$.

Solving the simultaneous equations leads to

$$
\begin{aligned}
I_{i}^{* *} & =\frac{(9 \gamma-(2-r)) \alpha-9 r \gamma \beta}{(9 \gamma-2)(9 \gamma-1)+r+(9 \gamma-1) r^{2}} \\
e_{i}^{* *} & =\frac{(9 \gamma-(2-r)(1+r)) \alpha-(18 \gamma-(2-r)(1+r)) \beta}{(9 \gamma-2)(9 \gamma-1)+r+(9 \gamma-1) r^{2}}
\end{aligned}
$$

\footnotetext{
${ }^{15}$ Notice the sequence of moves. For our results to hold, each upstream firm must choose whether to give out its technology before choosing effort levels, while the size of spillovers is not so essential.
} 
We can explicitly solve the game and derive the equilibrium profits, which are again messy (see Appendix): $\Pi_{i}^{U *}(Y, Y), \Pi_{i}^{D *}(Y, Y)$. Thus here we only examine how the exogenous variables ( $\alpha$ and $r$ ) affect the equilibrium profits. First, an increase in the degree of spillovers $(r)$ raises firm profitability. Second, because $\alpha=a-c$ and $\beta=w-c$, an increase in $\alpha$ reflects an increase in $a$, expanding the market size. As Matsushima and Zhao (2018) show, an increase in $\alpha$ does not always improve the profitability of each upstream firm in the absence of spillovers if $r$ is small enough (Figure 3).

[Figure 3 about here]

Note that the left panel in Figure 3 also shows several properties: i). An increase in the market size monotonically and significantly raises the profit of each upstream firm when the degree of spillovers is large enough, because the outside option of $D_{i}$ decreases with the degree of spillovers. ii). The spillover effect is more significant on the upstream firms than the downstream firms, caused by the former firms' investment to lower the outside option of the latter firms. iii). The spillover effect on the rival's efficiency is magnified, when the downstream firm also has a stronger incentive to raise its own option value (i.e., when $\alpha$ is large). In turn, an increase in $r$ enhances the incentive of each upstream firm to engage in cost-reducing activity, raising their profits.

We can explicitly derive the threshold value of $\beta$, denoted as $\beta(Y Y)$, at which $U_{i}$ 's profit when both upstream firms generate spillovers equals that when only $U_{j}$ generates spillover. A simple comparison gives:

Proposition $2 \Pi_{1}^{U *}(Y, Y)>\Pi_{1}^{U *}(N, Y)$ if and only if $\beta<\beta(Y Y)$, where $\beta(Y Y)$ is the threshold $\beta$ satisfying $\Pi_{1}^{U *}(Y, Y)=\Pi_{1}^{U *}(N, Y)$. Similarly, $\Pi_{2}^{U *}(Y, Y)>\Pi_{2}^{U *}(Y, N)$ if and only if $\beta<\beta(Y Y)$.

The threshold value $\beta(Y Y)$, and the difference between $\beta(Y Y)$ and $\beta(Y N)$ are summarized in Figure 4. From these threshold values, the decisions of the upstream firms de- 
pend on the exogenous values $\beta / \alpha$ and $r$. As $\beta / \alpha$ rises, the incentive of each downstream firm to increase its search effort becomes weaker, which in turn lowers the incentive of each upstream firm for technology spillovers.

[Figure 4 about here]

\subsection{The first stage: Endogenous spillover effects}

So far we have examined either one-way or two-way but exogenous giveaway of upstream technology. Next, we examine in the first stage, whether each upstream firm $U_{i}$ unilaterally decides to generate technological spillover to its rival upstream firm $U_{j}$ or not. ${ }^{16}$ Depending on the threshold values of $\beta$, we find:

Proposition 3 (i). If $\beta<\beta(Y Y)$, both $U_{1}$ and $U_{2}$ voluntarily generate spillovers; (ii). If $\beta>\beta(Y N)$, no upstream firm voluntarily generates spillover; and (iii). If $\beta(Y N)<\beta<\beta(Y Y)$, multiple equilibria exist.

Figure 5 shows, under high parameter values of $\beta / \alpha$, neither upstream firm is willing to give its technology out; Under intermediate values, both firms can either generate technology spillovers to the rival or not at all, i.e., multiple equilibria exist; Under low values of the same parameter ratio, each upstream firm has incentives to generate spillover in equilibrium.

[Figure 5 about here]

The logic can be understood as follows. As emphasized in the paragraph right after (11) in Section 3.2.2, a lower $\beta / \alpha$ enhances the incentives for the downstream firms to increase search efforts, which induces each upstream firm to generate spillovers to mitigate its downstream partner's incentive to search. As shown in Figure 6, the investment

16 It can be straightforwardly shown that $U_{j}$ does not have an incentive to refuse the unilateral spillover. 
of a spillover-generating upstream firm and that of a downstream firm are negatively correlated with $\beta / \alpha$.

[Figure 6 about here]

Note that investment spillover is a key reason for multiple equilibria under intermediate values of $\beta / \alpha$. In Figure 5, the lower line indicates the threshold value of $\beta / \alpha$ for which $U_{i}$ has incentives to generate spillovers given that $U_{-i}$ does not generate spillovers. As in (13), generating spillovers increases the rival upstream's investment because it raises the rival's quantity, diminishing its own incentive for unilateral spillover. However, the effect is almost canceled out by the decrease in the downstream partner's investment, which is shown by the gentle slope of the lower line in Figure 5.

Next, the threshold value of $\beta / \alpha$ for which $U_{i}$ has an incentive to generate spillover given that $U_{-i}$ also generates spillover, can be reflected by the upper curve in Figure 5, which is concave and shows the changes in the reactions of the upstream firms. Given that its rival generates spillovers, a firm's own spillover causes two effects: (i) the rival's free riding on the investment and (ii) the loss of its aggressive investment through unilaterally receiving spillovers. The free-riding effect is weaker than when only one upstream firm generates spillover (compare (18) with (13)), which increases its incentive for generating spillover. As a result, the threshold value of $\beta / \alpha$ rises above the level when no upstream firm generates spillover, leading to multiple equilibria. This effect, while positive, is however partially canceled out by the latter loss which increases with the degree of spillovers (see (13)), shifting down the upper curve of $\beta / \alpha$ for a higher $r$ in Figure 5 .

Further, the above results are obtained based on the assumption that the downstream firms' efforts are independent from each other (i.e., $e_{i}$ does not influence the outside option of $\left.D_{j}(i, j=1,2, j \neq i)\right)$. If on the contrary, $e_{i}$ also improves the outside option of $D_{j}$, then each upstream firm has a stronger incentive to generate positive spillovers, just to mitigate the efforts of the downstream firms. 
Finally, we check whether the voluntary spillover benefits the downstream firms. Simple calculations lead to:

Proposition $4 \Pi_{i}^{D *}(Y, Y)>\Pi_{i}^{D *}(N, N)$ if and only if $\beta<(9 \gamma-2) \alpha /((1+r)(9 \gamma-1))$.

Note here the upper bound of $\beta$ is higher than $\beta(Y Y)$, which implies the downstream firms benefit from such voluntary spillovers from the upstream firms.

\section{Conclusion}

We have investigated how strategic sourcing influences profitability in buyer-suppler relationships, and especially as an alternative to overcoming trading frictions. Specifically, we consider a bilateral duopoly with cost-reducing investments by the suppliers, and find that each supplier has an incentive to voluntarily generate technology spillovers to its rival if the buyer's cost to lower the outside wholesale price is small. Such an action causes a market size shrink within the vertical chain, which can benefit the supplier.

Our mechanism can have wide applications in various situations, such as in suppliers' incentives in cost reduction, quality improvement, upstream collaboration, technology spillovers and labor training, which remain as interesting topics for future research. Also, strategic sourcing in the context of our model is theoretically similar to improving the production technology at the downstream level and vertical integration with outside (second-best) suppliers, where the implication of our results can be applied.

Finally, we note some caveats. First, we have abstracted from commitment issues and strategic competition among suppliers, by modelling the second source as a purely competitive 'fringe'. The wholesale price set by outside fringe suppliers is negatively correlated to the degree of frictions. Chatain and Zemsky (2011) formulate frictions as a result of probabilistic randomness in the matching of buyers and suppliers. A lower wholesale price in the present model (set by outside suppliers) would represent a lower 
friction level in their terminology. Second, we have examined how buyers invest to improve procurement conditions given that they have options to procure their inputs from potential outside suppliers. As a future topic, it would be interesting to explicitly investigate the buyer decisions on bi-sourcing, as discussed in Emons (1996), Shy and Stenbacka (2003), Beladi and Mukherjee (2012) and Stenbacka and Tombak (2012). ${ }^{17}$

\footnotetext{
17 In the management literature, it is well established that manufacturers are willing to outsource in the absence of suppliers' cost advantage because outsourcing mitigates market competition (Cachon and Harker, 2002; Arya et al., 2008; Liu and Tyagi, 2011).
} 


\section{Appendix: The Equilibrium Profits in Section 3}

The equilibrium profits under the two scenarios of spillovers in Section 3 are as follows.

One-sided spillover The equilibrium profits of the firms are respectively,

$$
\begin{aligned}
& \Pi_{1}^{U *}(Y, N) \\
& =\frac{9 \gamma^{2}[(3 \gamma-1)(9 \gamma-(2-r)) \alpha-r(6 \gamma-1-3 \gamma r) \beta]^{2}}{2(9 \gamma-(2-r))^{2}((3 \gamma-1)(9 \gamma-1)+3 \gamma r)^{2}} \\
& -\frac{9 \gamma^{2}\left[(3 \gamma-1)(9 \gamma-(2-r)) \alpha-\left(2(3 \gamma-1)(9 \gamma-1)+(12 \gamma-1) r-3 \gamma r^{2}\right) \beta\right]^{2}}{2(9 \gamma-(2-r))^{2}((3 \gamma-1)(9 \gamma-1)+3 \gamma r)^{2}} \\
& -\frac{\gamma[(3 \gamma-1)(9 \gamma-(2-r)) \alpha-3 r(9 \gamma-2) \gamma \beta]^{2}}{(9 \gamma-(2-r))^{2}((3 \gamma-1)(9 \gamma-1)+3 \gamma r)^{2}} \\
& \Pi_{1}^{D *}(Y, N) \\
& =\frac{\gamma(9 \gamma-2)\left[(3 \gamma-1)(9 \gamma-(2-r)) \alpha-\left(2(3 \gamma-1)(9 \gamma-1)+(12 \gamma-1) r-3 \gamma r^{2}\right) \beta\right]^{2}}{2(9 \gamma-(2-r))^{2}((3 \gamma-1)(9 \gamma-1)+3 \gamma r)^{2}} \\
& +\frac{9 \gamma^{2}[(3 \gamma-1)(9 \gamma-(2-r)) \alpha-r(6 \gamma-1-3 \gamma r) \beta]^{2}}{2(9 \gamma-(2-r))^{2}((3 \gamma-1)(9 \gamma-1)+3 \gamma r)^{2}} \\
& \Pi_{2}^{U *}(Y, N) \\
& =\frac{\gamma(9 \gamma-2)\left[\left((3 \gamma-1)(9 \gamma-2)+3(4 \gamma-1) r+r^{2}\right) \alpha+3(1-2 r) r \gamma \beta\right]^{2}}{2(9 \gamma-(2-r))^{2}((3 \gamma-1)(9 \gamma-1)+3 \gamma r)^{2}} \\
& -\frac{9 \gamma^{2}}{2(9 \gamma-2)^{2}(9 \gamma-(2-r))^{2}((3 \gamma-1)(9 \gamma-1)+3 \gamma r)^{2}} \times \\
& \left\{\left((9 \gamma-2)^{2}(3 \gamma-1)+(9 \gamma-2)(6 \gamma-1) r+3 \gamma r^{2}\right) \alpha\right. \\
& \left.-\left(2(3 \gamma-1)(9 \gamma-1)(9 \gamma-2)+\left(81 \gamma^{2}-30 \gamma+2\right) r+6 \gamma r^{2}\right) \beta\right\}^{2}, \\
& \Pi_{2}^{D *}(Y, N) \\
& =\frac{\gamma}{2(9 \gamma-2)(9 \gamma-(2-r))^{2}((3 \gamma-1)(9 \gamma-1)+3 \gamma r)^{2}} \times \\
& \left\{\left((9 \gamma-2)^{2}(3 \gamma-1)+(9 \gamma-2)(6 \gamma-1) r+3 \gamma r^{2}\right) \alpha\right. \\
& \left.-\left(2(3 \gamma-1)(9 \gamma-1)(9 \gamma-2)+\left(81 \gamma^{2}-30 \gamma+2\right) r+6 \gamma r^{2}\right) \beta\right\}^{2} \\
& +\frac{9 \gamma^{2}\left[\left((3 \gamma-1)(9 \gamma-2)+3(4 \gamma-1) r+r^{2}\right) \alpha+3(1-2 r) r \gamma \beta\right]^{2}}{2(9 \gamma-(2-r))^{2}((3 \gamma-1)(9 \gamma-1)+3 \gamma r)^{2}} \text {. }
\end{aligned}
$$


Two-sided spillovers The equilibrium profits of the firms are respectively,

$$
\begin{gathered}
\Pi_{i}^{U *}(Y, Y)=\frac{9 \gamma^{2}\left[\left(9 \gamma-2+r+r^{2}\right) \alpha-r(1+r) \beta\right]^{2}}{2\left((9 \gamma-1)(9 \gamma-2)+r+(9 \gamma-1) r^{2}\right)^{2}} \\
-\frac{9 \gamma^{2}\left[\left(9 \gamma-2-r+r^{2}\right) \alpha-\left(2(9 \gamma-1)-r+r^{2}\right) \beta\right]^{2}}{2\left((9 \gamma-1)(9 \gamma-2)+r+(9 \gamma-1) r^{2}\right)^{2}} \\
-\frac{\gamma[(9 \gamma-2+r) \alpha-9 r \gamma \beta]^{2}}{\left((9 \gamma-1)(9 \gamma-2)+r+(9 \gamma-1) r^{2}\right)^{2}}, \\
\Pi_{i}^{D *}(Y, Y)=\frac{\gamma(9 \gamma-2)\left[\left(9 \gamma-2-r+r^{2}\right) \alpha-\left(2(9 \gamma-1)-r+r^{2}\right) \beta\right]^{2}}{2\left((9 \gamma-1)(9 \gamma-2)+r+(9 \gamma-1) r^{2}\right)^{2}} \\
+\frac{9 \gamma^{2}\left[\left(9 \gamma-2+r+r^{2}\right) \alpha-r(1+r) \beta\right]^{2}}{2\left((9 \gamma-1)(9 \gamma-2)+r+(9 \gamma-1) r^{2}\right)^{2}} .
\end{gathered}
$$

The threshold values in Propositions 1 and 2 The threshold values in Propositions 2 and 3 are given as

$$
\begin{aligned}
\beta(Y N) & =\frac{\alpha(9 \gamma-2)(9 \gamma-2+r)\left\{((9 \gamma-1)(3 \gamma-1)+3 \gamma r) \sqrt{A_{Y N}}-B_{Y N}\right\}}{C_{Y N}}, \\
\beta(Y Y) & =\frac{\alpha(9 \gamma-2+r)}{C_{Y Y}} \\
& \times\left\{((9 \gamma-1)(3 \gamma-1)+3 \gamma r)(9 \gamma-2)\left((9 \gamma-1)\left(9 \gamma-2+r^{2}\right)+r\right) \sqrt{A_{Y Y}}-B_{Y Y}\right\},
\end{aligned}
$$

where $A_{Y N} \equiv(9 \gamma-1)^{4}+6(3 \gamma-1)(9 \gamma-1)(9 \gamma-2) r+9 \gamma(9 \gamma-2) r^{2}, B_{Y N} \equiv(3 \gamma-1)(9 \gamma-$ 1) $\left(81 \gamma^{2}-18 \gamma-1\right)+9 \gamma\left(81 \gamma^{2}-30 \gamma+2\right) r+27 \gamma^{2} r^{2}, C_{Y N} \equiv 3(9 \gamma-1)\{6 \gamma(3 \gamma-1)(9 \gamma-1)(9 \gamma-$ $\left.2)-\left(6561 \gamma^{5}-1458 \gamma^{4}-1620 \gamma^{3}+612 \gamma^{2}-64 \gamma+2\right) r-6 \gamma\left(234 \gamma^{3}-24 \gamma+2\right) r^{2}-18 \gamma^{2} r^{3}\right\}$, $A_{Y Y} \equiv \gamma\left\{(9 \gamma-1)^{4}(9 \gamma-2)^{2} \gamma+2 \gamma(9 \gamma-2)(9 \gamma-1)\left(729 \gamma^{3}-81 \gamma^{2}-45 \gamma+7\right) r+\left(-124659 \gamma^{5}+\right.\right.$ $\left.121014 \gamma^{4}-43092 \gamma^{3}+7092 \gamma^{2}-543 \gamma+16\right) r^{2}+4\left(19683 \gamma^{5}-21141 \gamma^{4}+8343 \gamma^{3}-1485 \gamma^{2}+\right.$ $121 \gamma-4) r^{3}+\left(13122 \gamma^{5}-14580 \gamma^{4}+5751 \gamma^{3}-1134 \gamma^{2}+118 \gamma-4\right) r^{4}-2\left(13122 \gamma^{5}-14580 \gamma^{4}+\right.$ $\left.\left.6156 \gamma^{3}-1215 \gamma^{2}+114 \gamma-4\right) r^{5}+(9 \gamma-2)\left(27 \gamma^{2}-12 \gamma+1\right)^{2} r^{6}\right\}, B_{Y Y} \equiv \gamma\left\{(9 \gamma-1)^{2}(9 \gamma-\right.$ $2)^{3}\left(243 \gamma^{3}-135 \gamma^{2}+15 \gamma+1\right)+(9 \gamma-2)^{2}\left(59049 \gamma^{5}-34992 \gamma^{4}+5103 \gamma^{3}+243 \gamma^{2}-87 \gamma+4\right) r+$ $\left(3188646 \gamma^{7}-4782969 \gamma^{6}+3326427 \gamma^{5}-1303452 \gamma^{4}+296946 \gamma^{3}-38421 \gamma^{2}+2589 \gamma-70\right) r^{2}-$ $3\left(531441 \gamma^{7}-1417176 \gamma^{6}+1200663 \gamma^{5}-494262 \gamma^{4}+110970 \gamma^{3}-13662 \gamma^{2}+847 \gamma-20\right) r^{3}+$ $\left(-531441 \gamma^{6}+708588 \gamma^{5}-336798 \gamma^{4}+73143 \gamma^{3}-6966 \gamma^{2}+147 \gamma+10\right) r^{4}+\left(-177147 \gamma^{6}+\right.$ $\left.295245 \gamma^{5}-174960 \gamma^{4}+52974 \gamma^{3}-8883 \gamma^{2}+789 \gamma-28\right) r^{5}-(9 \gamma-1)^{2}\left(729 \gamma^{3}-513 \gamma^{2}+108 \gamma-\right.$ 
8) $\left.r^{6}\right\}, C_{Y Y} \equiv 3 \gamma\left\{6 \gamma(3 \gamma-1)\left(81 \gamma^{2}-27 \gamma-2\right)^{3}-\left(81 \gamma^{2}-27 \gamma+2\right)^{2}\left(6561 \gamma^{5}-2916 \gamma^{4}-\right.\right.$ $\left.810 \gamma^{3}+486 \gamma^{2}-56 \gamma+2\right) r-2(9 \gamma-1)^{2}\left(118098 \gamma^{6}-98415 \gamma^{5}+29160 \gamma^{4}-4212 \gamma^{3}+531 \gamma^{2}-\right.$ $72 \gamma+4) r^{2}-6\left(177147 \gamma^{7}-98415 \gamma^{6}+15039 \gamma^{5}-2916 \gamma^{4}+1593 \gamma^{3}-357 \gamma^{2}+32 \gamma-1\right) r^{3}-$ $\left(5314410 \gamma^{7}-5904900 \gamma^{6}+2742498 \gamma^{5}-676512 \gamma^{4}+93150 \gamma^{3}-6966 \gamma^{2}+260 \gamma-4\right) r^{4}-$ $\left(-2125764 \gamma^{7}+2834352 \gamma^{6}-1430298 \gamma^{5}+358668 \gamma^{4}-47547 \gamma^{3}+3222 \gamma^{2}-108 \gamma+2\right) r^{5}-$ $\left.18 \gamma\left(6561 \gamma^{5}-5103 \gamma^{2}+1944 \gamma^{3}-423 \gamma^{2}+48 \gamma-2\right) r^{6}-2 \gamma(9 \gamma-1)^{2}\left(729 \gamma^{3}-486 \gamma^{2}+99 \gamma-8\right) r^{7}\right\}$.

\section{References}

Amir, R., Evstigneev, I., and Wooders, J., 2003. Noncooperative versus cooperative R\&D with endogenous spillover rates. Games and Economic Behavior 42(2), pp. $183-207$.

Aoki, K. and Lennerfors, T.T., 2013. Whither Japanese keiretsu? The transformation of vertical keiretsu in Toyota, Nissan and Honda 1991-2011. Asia Pacific Business Review 19(1), pp. 70-84.

Arya, A., Mittendorf, B., and Sappington, D.E.M., 2008. The make-or-buy decision in the presence of a rival: Strategic outsourcing to a common supplier. Management Science 54(10), pp. 1747-1758.

Asanuma, B., 1985. The contractual framework for parts supply in the Japanese automotive industry. Japanese Economy 13(4), pp. 54-78.

Beladi, H. and Mukherjee, A., 2012. Market structure and strategic bi-sourcing. Journal of Economic Behavior and Organization 82(1), pp. 210-219.

Cachon, G.P. and Harker, P.T., 2002. Competition and outsourcing with scale economies. Management Science 48(10), pp. 1314-1333. 
Chatain, O. and Zemsky, P., 2011. Value creation and value capture with frictions. Strategic Management Journal 32(11), pp. 1206-1231.

Choi, J.P. 1993. Cooperative R\&D with product market competitors. International Journal of Industrial Organization, 11(4), pp. 535-551.

d'Aspremont, C. and Jacquemin, A. 1992. Cooperative and noncooperative R\&D in duopoly with spillovers. American Economic Review 78(5), pp. 1133-1137.

Davidson, C., 1988. Multiunit bargaining in oligopolistic industries. Journal of Labor Economics 6(3), pp. 397-422.

De Bondt, R., 1997. Spillovers and innovative activities. International Journal of Industrial Organization 15(1), pp. 1-28.

De Fraja, G., 1993. Strategic spillovers in patent races. International Journal of Industrial Organization 11(1), pp. 139-146.

Dyer, J.H., Nobeoka, K., 2000. Creating and managing a high-performance knowledgesharing network: The Toyota case. Strategic Management Journal 21(3), pp. 345367.

Emons, W., 1996. Good times, bad times, and vertical upstream integration. International Journal of Industrial Organization 14(4), pp. 465-484.

Feng, Q. and Lu, L.X., 2012. The strategic perils of low cost outsourcing. Management Science 58(6), pp. 1196-1210.

Fershtman, C. and Judd, K., 1987. Equilibrium incentives in oligopoly. American Economic Review 77(5), pp. 927-940. 
Gil-Moltó, M.J., Georgantzís, N., and Orts, V., 2005. Cooperative R\&D with endogenous technology differentiation. Journal of Economics 85 Management Strategy 14(2), pp. 461-476.

Harhoff, D., Henkel, J., and von Hippel, E., 2003. Profiting from voluntary information spillovers: How users benefit by freely revealing their innovations. Research Policy 32(10), pp. 1753-1769.

Horn, H. and Wolinsky, A., 1988. Bilateral monopolies and incentives for merger. RAND Journal of Economics 19(3), pp. 408-419.

Inderst, R., 2007. Leveraging buyer power. International Journal of Industrial Organization 25(5), pp. 908-924.

Inderst, T. and Shaffer, G., 2018. Managing channel profits when retailers have profitable outside options. Management Science. Published online in Articles in Advance 21 May 2018. https://doi.org/10.1287/mnsc.2017.2953

Inderst, R. and Valletti, T., 2009. Price discrimination in input markets. RAND Journal of Economics 40(1), pp. 1-19.

Iozzi, A. and Valletti, T., 2014. Vertical bargaining and countervailing power. American Economic Journal: Microeconomics 6(3), pp. 106-135.

Kamath, R.R. and Liker, J.K., 1994. A second look at Japanese product development. Harvard Business Review 72(6), pp. 154-165.

Kamien, M.I. and Zang, I., 2000. Meet me halfway: Research joint ventures and absorptive capacity. International Journal of Industrial Organization 18(7), pp. 995-1012. 
Katsoulacos, Y. and Ulph, D., 1998. Endogenous spillovers and the performance of research joint ventures. Journal of Industrial Economics 46(3), pp. 333-357.

Kultti, K. and Takalo, T., 1998. R\&D spillovers and information exchange. Economics Letters 61(1), pp. 21-23.

Liu, Y. and Tyagi, R., 2011. The benefits of competitive upward channel decentralization. Management Science 57(4), pp. 741-751.

Matsushima, N. and Shinohara, R., 2014. What factors determine the number of trading partners? Journal of Economic Behavior $\&$ Organization 106(1), pp. 428 441.

Matsushima, N. and Zhao, L., 2015. Strategic dual sourcing as a driver for free revealing of innovation. ISER Discussion Paper No. 936, Osaka University.

Matsushima, N. and Zhao, L., 2018. Market expansion may harm the supplier in a bilateral monopoly. ISER Discussion Paper No. 1040, Osaka University.

Milliou, C., 2009. Endogenous protection of R\&D investments. Canadian Journal of Economics 41(1), pp. 184-205.

Milliou, C. and Petrakis, E., 2007. Upstream horizontal mergers, vertical contracts, and bargaining. International Journal of Industrial Organization 25(5), pp. 963-987.

Milliou, C. and Petrakis, E., 2012. Vertical integration, knowledge disclosure and decreasing rival's cost. Departamento de Economía, Universidad Carlos III de Madrid, Economics Series, Working Paper 12-13.

Pacheco-de-Almeida, G. and Zemsky, P., 2012. Some like it free: Innovators' strategic use of disclosure to slow down competition. Strategic Management Journal 33(7), pp. $773-793$. 
Pastor, M. and Sandonís, J., 2002. Research joint ventures vs. cross licensing agreements: an agency approach. International Journal of Industrial Organization 20(2), pp. 215-249.

Pénin, J., 2007. Open knowledge disclosure: an overview of the evidence and economic motivations. Journal of Economic Surveys 21(2), pp. 326-348.

Pérez-Castrillo, J.D. and Sandonís, J., 1997. Disclosure of know-how in research joint ventures. International Journal of Industrial Organization 15(1), pp. 51-75.

Porter, M., 1980. Competitive Strategy: Techniques for Analyzing Industries and Competitors. Free Press, New York, NY.

Poyago-Theotoky, J., 1999. A note on endogenous spillovers in a non-tournament R\&D duopoly. Review of Industrial Organization 15(3), pp. 253-262.

Rockett, K., 2012. Perspectives on the knowledge-based society: An introduction to the special issue, Economics: The Open-Access, Open-Assessment E-Journal, 6(201235): pp. 1-26. Doi: 10.5018/economics-ejournal.ja.2012-35

Sako, M., 1996, Suppliers' association in the Japanese automobile industry: collective action for technology diffusion. Cambridge Journal of Economics 20(6), pp. 657671.

Shy, O. and Stenbacka, R., 2003. Strategic outsourcing. Journal of Economic Behavior and Organization 50(2), pp. 203-224.

Stenbacka, R. and Tombak, M., 2012. Make and buy: Balancing bargaining power. Journal of Economic Behavior and Organization 81(2), pp. 391-402.

Suzuki, K. 1993. R\&D spillovers and technology transfer among and within vertical 
keiretsu groups-evidence from the Japanese electrical machinery industry, International Journal of Industrial Organization 11(4), pp. 573-591.

Suzumura, K. 1992. Cooperative and noncooperative R\&D in an oligopoly with spillovers, American Economic Review 82(5), pp. 1307-1320.

Wilhelm, M.M., 2012. Managing coopetition through horizontal supply chain relations: Linking dyadic and network levels of analysis. Journal of Operations Management 29(7-8), pp. 663-676.

Wu, Z. and Choi, T.Y., 2005. Supplier-supplier relationships in the buyer-supplier triad: Building theories from eight case studies. Journal of Operations Management 24(1), pp. 27-52.

Wu, Z. Choi, T.Y., and M. J. Rungtusanatham, 2010. Supplier-supplier relationships in buyer-supplier-supplier triads: Implications for supplier performance. Journal of Operations Management 28(2), pp. 115-123.

Yoshida, S., 2015. Multi product competition in vertically related industries. ISER Discussion Paper No. 935, Osaka University. 


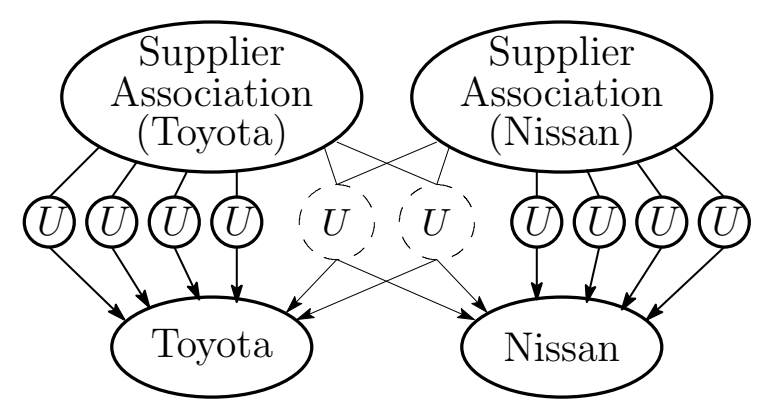

Figure 1: Supplier Associations in the Japanese automobile industry

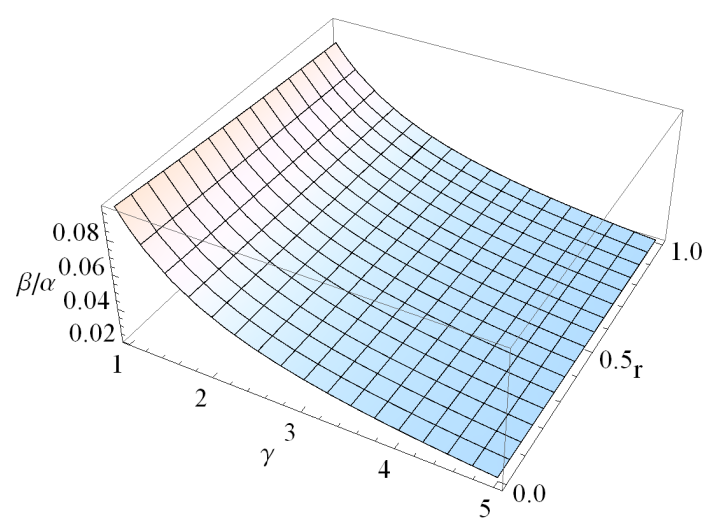

Figure 2: Condition for voluntary spillover to benefit $U_{1}$

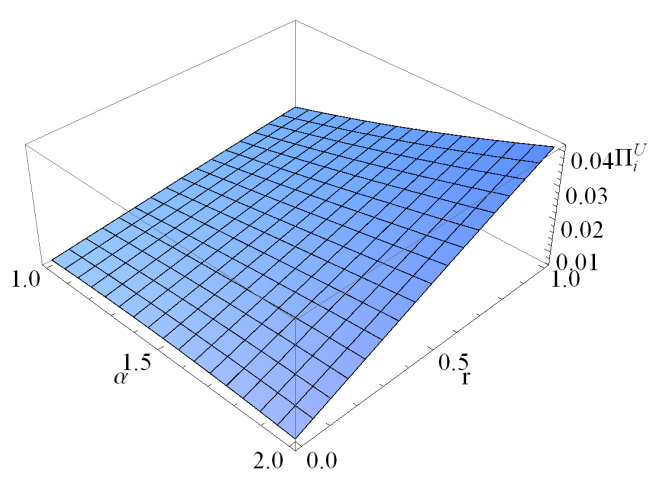

Upstream firm

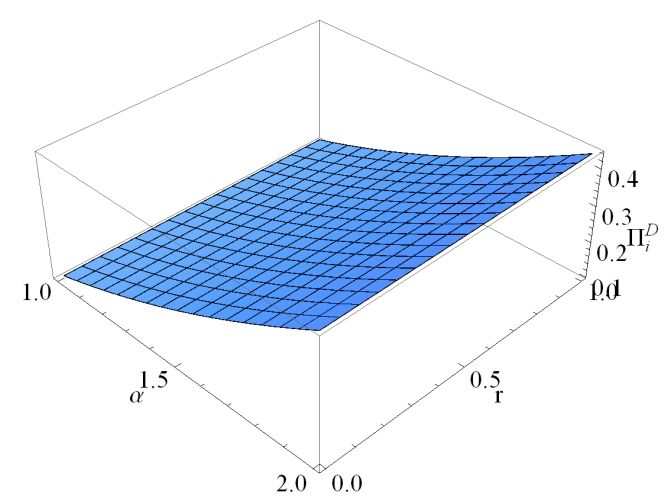

Downstream firm

Note: We set $\gamma=3$ and $\beta=1 / 20$ to draw the figures.

Figure 3: The profits of the upstream and downstream firms 

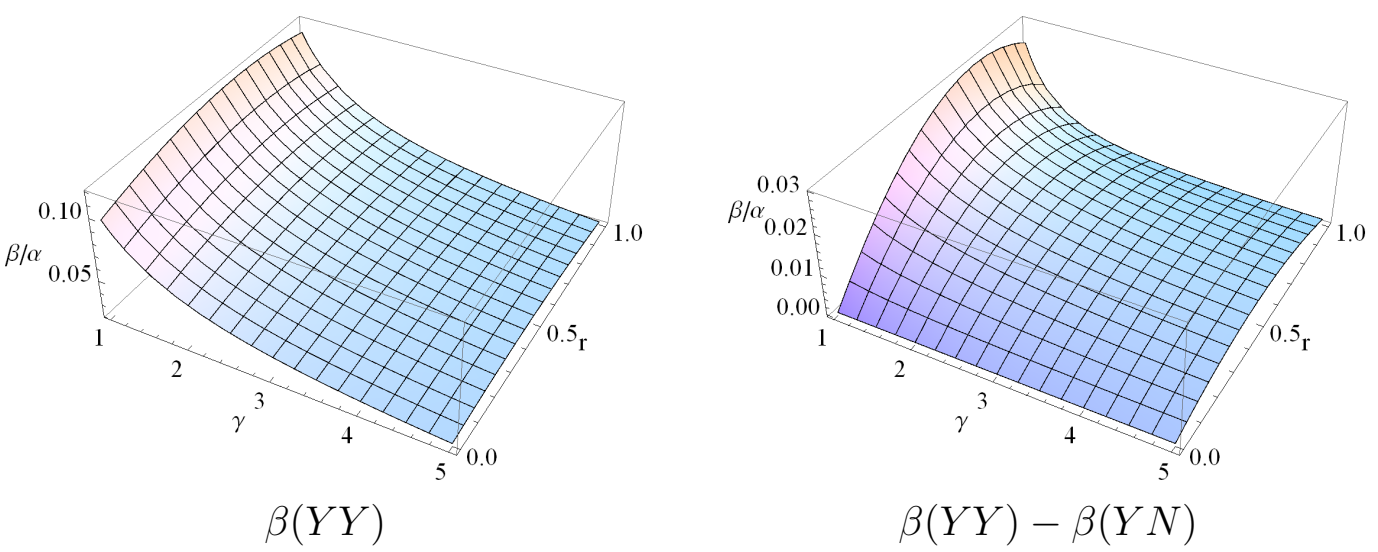

Figure 4: The conditions that upstream firms generate spillovers

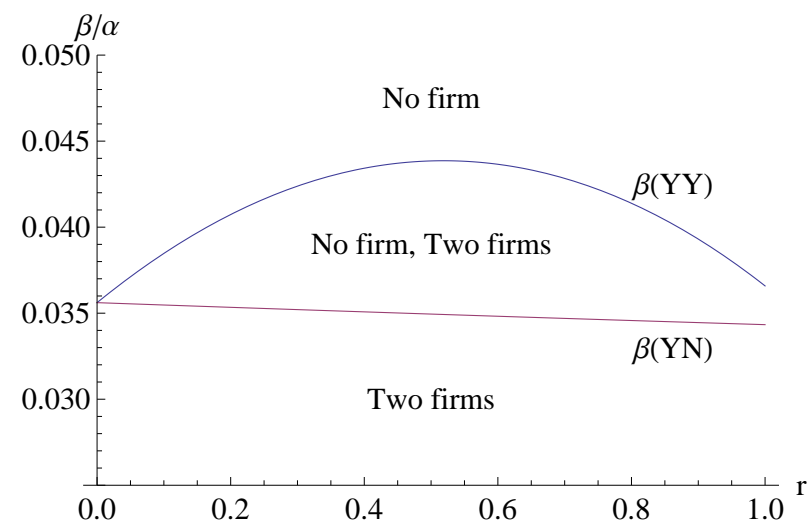

Figure 5: Endogenous determination of spillover effects $(\gamma=3)$

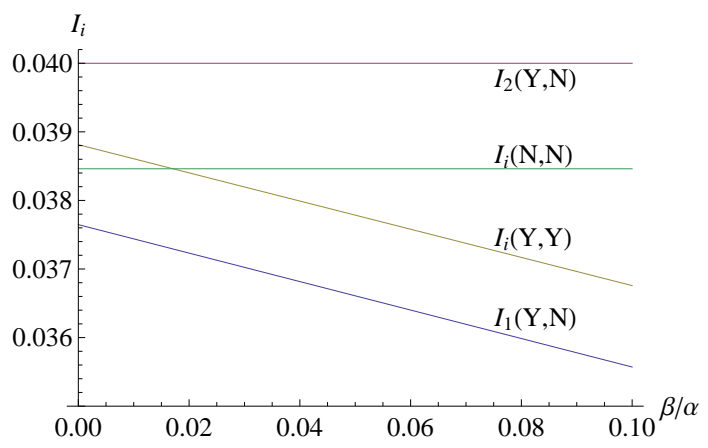

(Investment levels: upstream)

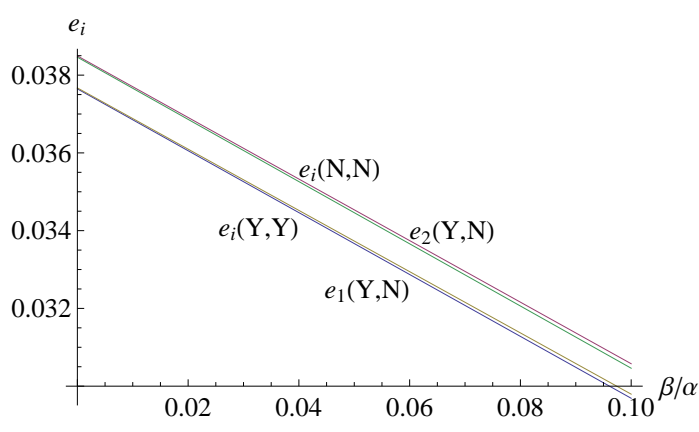

(Investment levels: downstream)

Figure 6: The equilibrium investment levels $(\gamma=3, r=1 / 2)$

$(Y, Y): \quad$ Both upstream firms generate spillovers.

$(Y, N)$ : Only $U_{1}$ generates spillover.

$(N, N)$ : No upstream firm generates spillover.

Note: $\quad e_{2}(Y, N)>e_{i}(N, N)>e_{i}(Y, Y)>e_{1}(Y, N)$ 